Journal of

Women's Health and Gynecology

\title{
The Risk of Teenage Motherhood Decreases in A Dose Response Fashion With Increasing SES: A Population-Based Study From British Columbia, Canada
} Jenny Fairthorne ${ }^{1,2, *}$, Gillian E Hanley ${ }^{1,3}$, Tim F Oberlander ${ }^{1}$

${ }^{1}$ British Columbia Children's Hospital Research Institute, University of British Columbia, Vancouver, Canada

${ }^{2}$ Telethon Kids Institute, University of Western Australia, Perth, Australia

${ }^{3}$ Department of Obstetrics and Gynaecology, University of British Columbia, Vancouver, Canada

${ }^{4}$ Department of Statistics, University of British Columbia, Vancouver, Canada

${ }^{\star}$ Corresponding author: Jenny Fairthorne, Department of Paediatrics, University of British Columbia (BC), BC Children's Hospital Research Institute, F602A, 4480 Oak St, Vancouver, BC, Canada; Tel: 604-875-2000; Email: jfairthorne@bcchri.ca

Received Date: February 11 2017; Accepted Date: March 4 2017; Published Date: March 62017

Citation: Jenny Fairthorne, et al. (2017) The Risk of Teenage Motherhood Decreases in A Dose Response Fashion With Increasing SES: A Population-Based Study From British Columbia, Canada. J Womens Health Gyn 4: 1-6.

\footnotetext{
Abstract

Background: Teenage mothers are more likely to be of low Socio-Economic Status (SES) but it is not known whether the risk abates abruptly in teenagers of middle SES or gradually over the range of SES. The health associations of teenage motherhood include poorer health behaviours during pregnancy such as increased use of tobacco and alcohol, and poorer nutrition. There are also increased obstetric risks, poorer child outcomes and poorer maternal health over the life-course. We hypothesized that the risk of teenage motherhood is greatest in those from the lowest SES decile and that this risk reduces with increasing SES.

Methods: We linked registry data from British Columbia and created SES deciles from tax file data derived from family disposable income.

Results: First-time mothers from the lowest SES decile were nearly twice as likely to be teenage [OR=1.91(95\% CI: 1.73 , 2.09)] than mothers of middle SES. With increasing SES deciles, the odds of teenage motherhood reduced in a negative linear fashion (P-value $<0.0005)$.

Conclusions: Girls of lowest SES are at highest risk of teenage motherhood and this risk reduces gradually with increasing SES decile. The associated negative, life-long health effects in mother and child necessitate the need to target high risk groups with interventions aimed at reducing pregnancy rates among teenage girls of lower SES. Girls and boys in years nine and ten at high schools in the lowest socio-economic areas could benefit from public health interventions aimed at reducing their risk of becoming a teenage parent.

Keywords: Teenage; Birth; Mother; Socio-economic status; Population; Canada
}

(C)2017 The Authors. Published by the JScholar under the terms of the Creative Commons Attribution License http://creativecommons.org/licenses/ by $/ 3.0 /$, which permits unrestricted use, provided the original author and source are credited. 


\section{Introduction}

Teenage mothers are more likely to be of low socioeconomic status (SES) [1,2]. In a US study [1], the SES of 900 nulliparous teenage girls and more than 7,500 nulliparous women aged 20 to 25 years, was compared during their pregnancies. Investigators constructed SES quintiles based on maternal and paternal education, occupation and household income. Nearly half of the teenagers were of the lowest SES quintile while a further third were of the second lowest quintile. The incidence of teenage motherhood decreased further with increasing SES with $14 \%$ in the middle quintile and 5\% and $0.5 \%$ in the upper two quintiles respectively. The figures indicate a negative trend but whether it was linear or otherwise was not investigated. The second study [2] used data of more than 6,000 Canadian mothers who gave birth in 2006 and three income groups (high, medium and low) were created as a proxy for SES. Compared to older mothers, teenage mothers were about six and a half times more likely to come from the low income group and about two and a half times more likely to come from the medium income group [2]. Again, there is a suggestion of a negative trend over increasing SES but this was not analysed. An international collaboration [3], including Canada and four other western countries, used survey and other data to investigate teenage birth with education as a proxy for SES. In all countries, the rate of teenage birth was highest in the lowest tertile and lowest in the highest tertile. However, the rate reduced abruptly with transition from the lowest to the middle tertile, indicating that the trend was not linear. Again, no analysis of a trend was performed. A review examined 20 studies pertaining to the risk factors for teenage pregnancy and while socioeconomic disadvantage was the most consistently identified factor, there was no indication of whether the risk reduced more-or-less equally in middle and high SES groups or whether there was a linear or other reduction with increasing SES.

Compared to pregnancy in other age-groups, teenage pregnancy has increased health risks for both mother and infant. First, teenage pregnancy is also associated with poorer health behaviours. A review [4] examined health behaviours during the pregnancies of teenagers in UK and found that increased use of tobacco and alcohol and poorer nutrition were more common in these mothers than others. Second, teenage pregnancy is associated with poorer maternal health outcomes. The same review [4] described higher risks of obstetric complications such as hypertension, pre-eclampsia, urinary tract infection and anaemia. The increased risk of negative health outcomes for teenage mothers continues into adulthood and old-age with an increased risk of cardiovascular disease [5] and more generally, poorer physical health compared to other women [6]. Finally, teenage pregnancy is associated with poorer child outcomes. In a retrospective cohort study of nearly four million US mothers younger than 25 years, the infants of teenage mothers were at increased risk of being born preterm, neonatal death and low birth weight [7]. Over time, the higher risk of negative outcomes continued with a twofold higher risk of death during each of infancy, childhood and adolescence [8]. Understanding the social determinants of teenage pregnancy may help in managing these risks yet we found only one study [1] that assessed the rate of teenage births over the range of SES using quintiles and this did not investigate any trends over increasing SES. Hence, we don't know whether high rates of teenage pregnancy are largely restricted to the lowest decile(s) or whether the rate gradually recedes with increasing SES. In this capacity, a measure of SES which used more than five levels, such as deciles, would be preferable since the increased number of levels would enable a trend to be better described. This knowledge is important since it would provide valuable information about socio-economic risk factors for teenage pregnancy and the identification of vulnerable groups who might benefit from interventions to reduce their likelihood of teen pregnancy. Hence, we hypothesized that mothers of low SES are more likely to first give birth as a teenager than mothers of middle SES. We also hypothesized that with increasing SES, the odds of first giving birth as a teenager are successively reduced with increasing SES and that mothers of the highest SES group are least likely to have had a child as a teenager.

\section{Methods}

\section{Data and inclusion criteria}

After ethical approval, we were supplied data from Population Data BC. These data had been previously shown to be complete, accurate and valid [9-11] and originated from the Births Registry [12], BC Perinatal Data Registry [13], Medical Services Provision Registry [14] and the Census Registry [15]. We removed the records of all mothers who were multiparous from the 1999-2009 BC Birth Cohort. Full details of this cohort are supplied in our previous paper [16]. We used the resultant data-set in this nested retrospective cohort study comprising mothers whose first child was born in BC from January 1, 1999 to December 31, 2009.

\section{Variables}

Our outcome variable, maternal age at the birth of the child, had the four levels of: less than 20 years; 20 to 29 years; 30 to 39 years and 40 years or older. From tax-file data, we accessed equivalised family disposable income for each provincial postcode which contains about 1,700 households. These had been averaged and then ranked into 1,000 levels [17]. We created a ten-level proxy for SES. By combining the lowest 100 bands, we formed Decile- 1 to represent the most disadvantaged group. Combining the next 100 bands, we formed Decile- 2 and so on, with Decile-10 representing the most advantaged women.

\section{Analyses}

Using multinomial logistic regression with Decile-6 as the comparator and 30 to 39 year old mothers as the base group, we assessed the odds ratios (ORs) of each level of maternal age by SES. We reduced our significance level from the usual 0.05 to 0.005 since we performed multiple comparisons over three levels [18]. We also investigated the linear significance of the relationship within maternal age groups using multinomial logistic regression. All ORs are tabulated but we report only significant ORs. Whilst our primary interest was teenage births, we compared the heterogeneity of other age groups, having a similar trend over SES, to the teenage group. 
Our underlying objective with such a comparison would be to improve our understanding of the trend within the teenage group. STATA14 was used for all analyses.

\section{Results}

In the cohort were 155,091 mothers and of these, 8,088 (5.2\%) were teenage ( $<20$ years) See Table 1 .

\section{Teenage mothers}

Compared to 30 to 39 year old mothers from Decile-6, teenage mothers were nearly twice as likely to come from Decile-1 [OR=1.91(95\% CI: 1.73, 2.09)] with 38\% more likely to come from Decile-2 [OR=1.38(95\% CI: $1.25,1.52)]$ and $29 \%$ more likely to come from Decile-3 [OR=1.29(95\% CI: $1.17,1.43)]$. At the other end of the scale, teenage mothers were $21 \%$ less likely to come from Decile- 8 [OR $=0.79$ (95\% CI: 0.71 , $0.88)$ ], $19 \%$ less likely to come from Decile- 9 [OR $=0.81(95 \%$ CI: $0.72,0.90)]$ and $37 \%$ less likely to come from Decile-10 [OR=0.63(95\% CI: $0.56,0.71)]$ (Table 2). Over Decile-1 to Decile-10, there was evidence of a negative linear trend associated with being a teenage mother with a Z-score of -9.04 and a p-value $<0.0005$ (Figure 1).

\section{Other mothers}

Mothers from 20 to 29 years were $28 \%$ more likely to be from Decile-1 [OR=1.28(95\% CI: $1.22,1.34)] ; 26 \%$ more likely to be from Decile-2 [OR=1.26(95\% CI: $1.21,1.32)]$; $23 \%$ more likely to be from Decile-3 [OR $=1.23$ (95\% CI: 1.18 , 1.29)] and $14 \%$ more likely to be from Decile-4 [OR $=1.14(95 \%$ CI: $1.09,1.19]$ than comparator mothers. Further, mothers from 20 to 29 years were $6 \%$ less likely to be from Decile-7 [OR $=0.94(95 \%$ CI: $0.90,0.98] ; 8 \%$ less likely to be from Decile-8 [OR=0.92(95\% CI: 0.87, 0.96)]; 17\% less likely to be from Decile-9 [OR $=0.83(95 \%$ CI: $0.80,0.88)]$ and $29 \%$ less likely to be from Decile-10 [OR=0.71(95\% CI: $0.68,0.75)]$ than comparator mothers (Table 2). With increasing SES, there was evidence of a negative linear trend associated with being a mother from 20 to 29 years old with a Z-score of -28.37 and a p-value $<0.0005$ (Figure 1).

\section{Comparing teenage mothers to 20-29 year old moth-} ers

Teenage mothers were $49 \%$ more likely to come from Decile- 1 than mothers aged from 20 to 29 years (Table 3).

Table 1: Maternal age at the birth of the first child by SES

\begin{tabular}{|c|c|c|c|c|c|}
\hline SES decile & $<20$ years & 20-29 years & $30-39$ years & $>40$ years & Total \\
\hline 1 & $\begin{array}{l}1,321 \\
(16.3 \%)\end{array}$ & $\begin{array}{l}8,479 \\
(11.4 \%)\end{array}$ & $\begin{array}{l}6,328 \\
(9.3 \%)\end{array}$ & $\begin{array}{l}378 \\
(9.1 \%)\end{array}$ & $\begin{array}{l}16,506 \\
(10.6 \%)\end{array}$ \\
\hline 2 & $\begin{array}{l}1,037 \\
(12.8 \%)\end{array}$ & $\begin{array}{l}9,097 \\
(12.2 \%)\end{array}$ & $\begin{array}{l}6,848 \\
(10.0 \%)\end{array}$ & $\begin{array}{l}393 \\
(9.5 \%)\end{array}$ & $\begin{array}{l}17,375 \\
(11.2 \%)\end{array}$ \\
\hline 3 & $\begin{array}{l}995 \\
(12.3 \%)\end{array}$ & $\begin{array}{l}9,097 \\
(12.2 \%)\end{array}$ & $\begin{array}{l}7,025 \\
(10.3 \%)\end{array}$ & $\begin{array}{l}389 \\
(9.4 \%)\end{array}$ & $\begin{array}{l}17,506 \\
(11.3 \%)\end{array}$ \\
\hline 4 & $\begin{array}{l}872 \\
(10.8 \%)\end{array}$ & $\begin{array}{l}8,390 \\
11.3(\%)\end{array}$ & $\begin{array}{l}6,996 \\
(10.3 \%)\end{array}$ & $\begin{array}{l}365 \\
(8.8 \%)\end{array}$ & $\begin{array}{l}16,623 \\
(10.7 \%)\end{array}$ \\
\hline 5 & $\begin{array}{l}795 \\
(9.8 \%)\end{array}$ & $\begin{array}{l}7,486 \\
(10.0 \%)\end{array}$ & $\begin{array}{l}7,060 \\
(10.3 \%)\end{array}$ & $\begin{array}{l}391 \\
(9.4 \%)\end{array}$ & $\begin{array}{l}16,146 \\
(10.4 \%)\end{array}$ \\
\hline 6 & $\begin{array}{l}781 \\
(9.7 \%)\end{array}$ & $\begin{array}{l}7,486 \\
(10.0 \%)\end{array}$ & $\begin{array}{l}7,128 \\
(10.4 \%)\end{array}$ & $\begin{array}{l}449 \\
(10.9 \%)\end{array}$ & $\begin{array}{l}15,844 \\
(10.2 \%)\end{array}$ \\
\hline 7 & $\begin{array}{l}667 \\
(8.3 \%)\end{array}$ & $\begin{array}{l}6,996 \\
(9.4 \%)\end{array}$ & $\begin{array}{l}7,086 \\
(10.4 \%)\end{array}$ & $\begin{array}{l}431 \\
(10.4 \%)\end{array}$ & $\begin{array}{l}15,180 \\
(9.8 \%)\end{array}$ \\
\hline 8 & $\begin{array}{l}604 \\
(7.5 \%)\end{array}$ & $\begin{array}{l}6,695 \\
(9.0 \%)\end{array}$ & $\begin{array}{l}6,697 \\
(9.9 \%)\end{array}$ & $\begin{array}{l}411 \\
(9.9 \%)\end{array}$ & $\begin{array}{l}14,677 \\
(9.5 \%)\end{array}$ \\
\hline 9 & $\begin{array}{l}596 \\
(7.4 \%)\end{array}$ & $\begin{array}{l}5,907 \\
(7.9 \%)\end{array}$ & $\begin{array}{l}6,738 \\
(9.9 \%)\end{array}$ & $\begin{array}{l}452 \\
(10.9 \%)\end{array}$ & $\begin{array}{l}13,693 \\
(8.8 \%)\end{array}$ \\
\hline 10 & $\begin{array}{l}420 \\
(5.2 \%)\end{array}$ & $\begin{array}{l}4,556 \\
(6.1 \%)\end{array}$ & $\begin{array}{l}6,084 \\
(8.9 \%)\end{array}$ & $\begin{array}{l}481 \\
(11.6 \%)\end{array}$ & $\begin{array}{l}11,541 \\
(7.4 \%)\end{array}$ \\
\hline Total & $\begin{array}{l}8,088 \\
(100 \%)\end{array}$ & $\begin{array}{l}74,603 \\
(100 \%)\end{array}$ & $\begin{array}{l}68,260 \\
(100 \%)\end{array}$ & $\begin{array}{l}4,140 \\
(100 \%)\end{array}$ & $\begin{array}{l}155,091 \\
(100 \%)\end{array}$ \\
\hline
\end{tabular}


Table 2: Odds ratios of maternal age by SES

\begin{tabular}{|c|c|c|c|c|}
\hline SES & $30-39$ years & $<20$ years & 20-29 years & $>40$ years \\
\hline 1 & $\ldots$ & $1.91(1.73,2.09)^{\star * *}$ & $1.28(1.22,1.34)^{\star * *}$ & $0.95(0.82,1.09)$ \\
\hline 2 & $\ldots$ & $1.38(1.25,1.52)^{\star * *}$ & $1.26(1.21,1.32)^{\star * *}$ & $0.91(0.79,1.05)$ \\
\hline 3 & $\ldots$ & $1.29(1.17,1.43)^{\star * *}$ & $1.23(1.18,1.29)^{\star * *}$ & $0.88(0.76,1.01)$ \\
\hline 4 & $\ldots$ & $1.14(1.03,1.26)$ & $1.14(1.09,1.19)^{\star * *}$ & $0.83(0.72,0.95)$ \\
\hline 5 & $\ldots$ & $1.03(0.93,1.14)$ & $1.07(1.02,1.12)$ & $0.88(0.76,1.01)$ \\
\hline \multicolumn{5}{|c|}{ Comparator group } \\
\hline 7 & $\ldots$ & $0.86(0.77,0.96)$ & $0.94(0.90,0.98)^{\star \star}$ & $0.97(0.84,1.11)$ \\
\hline 8 & $\ldots$ & $0.79(0.71,0.88)^{* * *}$ & $0.92(0.87,0.96)^{* * *}$ & $0.94(0.82,1.07)$ \\
\hline 9 & $\ldots$ & $0.81(0.72,0.90)^{\star * *}$ & $0.83(0.80,0.88)^{* * *}$ & $1.06(0.93,1.22)$ \\
\hline 10 & $\ldots$ & $0.63(0.56,0.71)^{* * *}$ & $0.71(0.68,0.75)^{\star * *}$ & $1.26(1.10,1.43)^{\star \star}$ \\
\hline
\end{tabular}

SES, socio-economic status; ${ }^{* *}, \mathrm{P}$-value $<0.005 ;{ }^{\star * *}, \mathrm{P}$-value $<0.0005$

Table 3: A comparison of teenage mothers to 20-29 year old mothers

\begin{tabular}{|l|l|l|}
\hline SES & $20-29$ years & $<20$ years \\
\hline 1 & $\ldots$. & $1.49(1.36,1.64)^{\star * *}$ \\
\hline 2 & $\ldots$. & $1.09(0.99,1.20)$ \\
\hline 3 & $\ldots$. & $1.05(0.95,1.16)$ \\
\hline 4 & $\ldots$. & $1.00(0.90,1.10)$ \\
\hline 5 & $\ldots$. & $0.96(0.87,1.07)$ \\
\hline 6 & $\ldots$ & $0.91(0.82,1.02)$ \\
\hline 7 & $\ldots$ & $0.86(0.77,0.97)$ \\
\hline 8 & $\ldots$ & $0.97(0.86,1.08)$ \\
\hline 9 & $\ldots$ & $0.88(0.78,1.00)$ \\
\hline 10 & $\ldots$. &
\end{tabular}

SES, socio-economic status; ${ }^{* * *}$, P-value $<0.0005$.

Figure 1: Socio-economic comparison of nulliparous teenage and 20-29 year old mothers

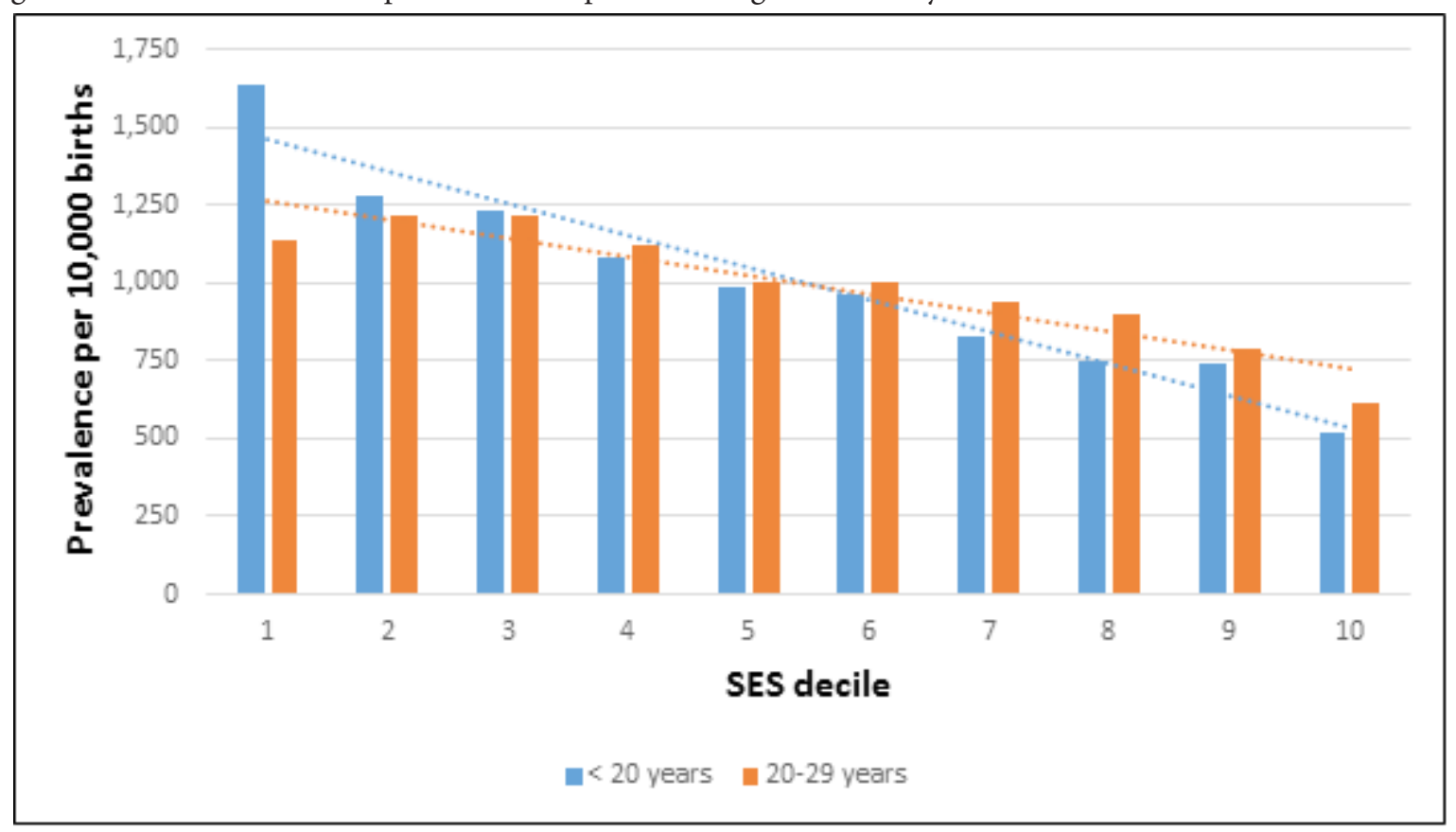

SES, socio-economic status; < 20 years, maternal age at birth of the first child is less than 20 years.

Note: Linear trend line is the colour-matched dotted line. 


\section{Discussion}

\section{Teenage mothers}

In support of our first hypothesis, we found that teenagers of lowest SES were nearly twice as likely to first give birth as a teenager than mothers of middle SES. In the US, Mollborn et al. [1] had similar but more extreme findings with about $47 \%$ of teenage mothers in the lowest two quintiles. In contrast, in this study only about $30 \%$ of mothers were from the lowest two quintiles. A Canadian study [2] also found a higher percentage of teenage mothers in the lowest SES category. Using a threelevel household income variable to estimate SES, investigators attributed about $74 \%$ of teenage mothers to the lowest tertile. Correspondingly, in our study, only $43 \%$ of teenage mothers were in the lowest three deciles. A reason to account for the differences between our study and the other two might be because the others used surveys and relied on maternal report. Teenage participants would have given their personal incomes which would likely be lower than the equivalised family-based measure that we used, particularly when the teenager resided with her parents. We conclude that teenage mothers are significantly more likely to come from the lowest SES decile.

Our results also strongly support our second hypothesis. Apart from Decile- 8 to Decile- 9 where there was a small increase (0.79 to 0.81$)$, we observed that ORs reduced with each successive SES decile, from 1.91 in Decile- 1 to a low of 0.63 in Decile-10 (Figure 1) and the corresponding p-value of the trend was less than 0.0005 . Other researchers $[1,2]$ have found the proportion of teenage mothers was highest in the lowest SES group and that the proportion reduced with increasing SES groups. However, the extent of the trend has been largely camouflaged since the number of groups was always five or less. In our study, we noted that teenage mothers had increased odds of being of below the median income (in Decile- 5 or less) and equal or reduced odds being above the median income (in Decile-6 or higher). Ours is the first study to formally identify a strong negative trend of the ORs of a teenage birth over an increasing range of ten SES deciles.

The trends over increasing SES in teenage mothers and mothers from 20 to 29 years are both negative and linear, though they differ in that the trend is steeper (or more pronounced) in the teenage mothers. Furthermore, teenage mothers were nearly $50 \%$ more likely to come from Decile- 1 than 20 to 29 year old mothers. In combination, these results indicate that coming from a disadvantaged back-ground is more strongly related to the risk of teenage motherhood and that the risk reduces more quickly for teenage mothers than mothers from 20 to 29 years.

There are likely to be many reasons for the strong negative linear trend over increasing SES decile of the odds of a teenage mother. One study inferred that the children of lower SES parents were less likely to be exposed to health-promoting behaviours and more likely to be exposed to risky behaviours [19]. From this stance, and in terms of contraceptive use, teenagers from Decile-1 might have less knowledge of safe sexual practices and less knowledge and confidence to access contraceptives [5] which would predispose these girls to more unplanned pregnancies than girls from higher deciles.
Apart from ascribing lower SES as a correlate of teenage pregnancy, a systematic review ascribed low educational levels and disrupted family structure as risk factors [20]. Qualitative researchers have described how disillusioned teenage girls of lower socio-economic backgrounds sometimes choose pregnancy in the hope of improving their lifestyles [21]. An intervention aimed at reducing the rate of teenage pregnancy could involve work-shops for girls and boys in years nine and ten at high schools in the lowest socio-economic areas. Here, the leader and participants could discuss the difficulties associated with teenage parenthood and information pertaining to contraception and the means of accessing contraceptives shared.

\section{Conclusion}

Our findings indicate that girls of lowest SES decile are particularly vulnerable to teen pregnancy and that this risk gradually reduces over increasing SES. The associated negative, life-long health effects of both mother and child necessitate the need to target the most vulnerable groups to reduce the likelihood of teen pregnancy.

\section{Disclaimer}

All inferences, opinions, and conclusions drawn in this manuscript are those of the authors, and do not reflect the opinions or policies of the Data Stewards at Population Data BC.

\section{Ethics}

Approval for this research was obtained from the Behavioural Research Ethics Board [22] at the University of British Columbia. 


\section{References}

1) Mollborn S, Dennis J. ( 2012) Investigating the life situations and development of teenage mothers' children: evidence from the ECLSB. Population Research and Policy Review 31: 31-66.

2) Al-Sahab B, HeifetzHala M, Bohr Y, Connolly J. (2012) Prevalence and characteristics of teen motherhood in Canada. Maternal and Child Health Journal. 16: 228-234.

3) Singh S, Darroch JE, Frost JJ. (2001) Socioeconomic disadvantage and adolescent women's sexual and reproductive behavior: the case of five developed countries. Fam Plann Perspect 33 :251-289.

4) Paranjothy S, Broughton H, Adappa R, Fone D (2009) Teenage pregnancy: Who suffers? Arch Dis Child 94: 239-245.

5) Cohen S, Janicki-Deverts D, Chen E, Matthews K (2010) Childhood socioeconomic status and adult health. Ann N Y Acad Sci 1186: 37-55.

6) Patel P, Sen B (2012) Teen motherhood and long-term health consequences. Matern Child Health J $16: 1063-1071$.

7) Chen X, Wen S, Fleming N, Demissie K, Rhoads G, et al. (2007) Teenage pregnancy and adverse birth outcomes: a large population based retrospective cohort study. Int J Epidemiol. 36: 368-373.

8) Jutte D, Roos N, Brownell M, Briggs G, MacWilliam L, et al. (2010) The ripples of adolescent motherhood: social, educational, and medical outcomes for children of teen and prior teen mothers. Acad Pediatr 10: 293-301.

9) Juurlink D, Preyra C, Croxford R, Chong A, Austin P, et al. (2006) Canadian Institute for Health Information Discharge Abstract Database: a validation study. Institute for Clinical Evaluative Sciences Investigative Report.

10) Frosst G, Hutcheon J, Joseph K, Kinniburgh B, Johnson C, et al. (2015) Validating the British Columbia Perinatal Data Registry: a chart re-abstraction study. BMC Pregnancy Childbirth 15: 123.

11) Hu W (1996) Diagnostic codes in MSP claim data. Victoria, BC: Government of British Columbia.

12) BC Vital Statistics Agency (2014) Vital Statistics Births. V2: Population Data BC.

13) Perinatal Services BC. British Columbia Perinatal Data Registry (2015) Population Data BC.

14) BC Ministry of Health. (2015) Medical Services Plan (MSP) Payment Information File V2 extracted 2015-02-17: Population Data BC.

15) Population Data BC. Services for Researchers. Vancouver, BC.

16) Fairthorne J, Hanley GE, Brant R, Oberlander TF. (2017) Mothers of the lowest and highest socio-economic deciles are at increased risk of hospitalizations associated with depression during the perinatal period: a retrospective cohort study. Manuscript submitted for publication.

17) Population Data BC (2015) Income band data: extracted from census_geocodes collection 2015-04-10 Vancouver, BC.

18) Napierala M (2012) What is the Bonferroni correction? American Academy of Orthopedic Surgeons. 6:40.

19) Cohen S, Janicki-Deverts D, Chen E, Matthews KA (2010) Childhood socioeconomic status and adult health. Annals of the New York Academy of Sciences. 1186: 37-55.

20) Imamura $M$, Tucker J, Hannaford $P$, Da Silva $M$, Astin $M$, Wyness L, et al. (2007) Factors associated with teenage pregnancy in the European Union countries: a systematic review. Eur J Public Health 17: 630-636.

21) Zubrick S, Silburn S (2006) Improving the educational experiences of Aboriginal children and young people. Perth, Australia: Telethon Kids Institute.

22) University of British Columbia (BC) (2016) Behavioural Research Ethics.

\section{Submit your manuscript to a JScholar journal} and benefit from:

ब Convenient online submission

- Rigorous peer review

I Immediate publication on acceptance

q Open access: articles freely available online

ฯ High visibility within the field

ब Better discount for your subsequent articles

Submit your manuscript at

http://www.jscholaronline.org/submit-manuscript.php 